\title{
INVESTIGATION OF WEAR RESISTANCE OF COMPOSITE ALLOYS UNDER THE CONDITIONS OF GAS-ABRASIVE WEAR AT ELEVATED TEMPERATURES
}

\author{
A.P. ZHUDRA \\ E.O. Paton Electric Welding Institute, NASU \\ 11 Bozhenko Str., 03680, Kiev, Ukraine. E-mail: office@paton.kiev.ua
}

\begin{abstract}
Given are the results of laboratory investigations of wear resistance of composite alloys, based on fused tungsten carbides $\mathrm{WC}+\mathrm{W}_{2} \mathrm{C}$ (relite), under conditions of gas-abrasive wear. Given is the technical characteristic of laboratory stand OB-876Ts for tests of deposited metal for gas-abrasive wear. The scheme of tests was developed, maximum corresponding to real conditions of service of parts during the effect of abrasive flow within the temperature range of $25-450{ }^{\circ} \mathrm{C}$. It was established that wear of composite alloys bears a selective, cyclic character and does not essentially depend on properties and hardness of matrix at small attack angles. The application of tungsten carbide with spherical granules increases wear resistance of composite alloy, and the increase in temperature up to $400{ }^{\circ} \mathrm{C}$ considerably decreases it due to oxidation of carbide component of alloys. At room temperature the wear resistance of composite alloy 2.7 times exceeds the wear resistance of nickel carbide chromium alloy. 9 Ref., 3 Tables, 3 Figures.
\end{abstract}

Keywords: gas-abrasive wear, composite alloys, fused tungsten carbide, spherical granules, matrix, microhardness, plasma-powder surfacing, relative wear resistance, test stand

The present work is the continuation of the earlier investigations, performed at the E.O. Paton Electric Welding Institute, on gas-abrasive wear of different types of hardfacing alloys [1-4], among which the composite alloys on the base of fused tungsten carbides $\mathrm{WC}+\mathrm{W}_{2} \mathrm{C}$ (relite) are of a peculiar interest. These alloys are featured by a unique wear resistance and widely applied for deposition of drilling tool and a number of critical parts in metallurgy and machine building. In work [2] the investigations of wear resistance of such alloys under the conditions of gas-abrasive wear were conducted in machine OB-876 [5] at the temperature of $400{ }^{\circ} \mathrm{C}$ on cylindrical specimens of $60 \mathrm{~mm}$ diameter with different compositions of matrix alloys, reinforced with fused tungsten carbides by granulation from 0.18 to $2 \mathrm{~mm}$. The specimens were manufactured using laboratory method in induction furnace by pouring the granules of crushed tungsten carbide through the layer of flux with the next cutting out of the most reinforced areas by the anodemechanical method. The composite alloys produced on the specimens in such a way are considerably different from real ones deposited using the arc or gas method. Therefore, there was an interest to investigate the wear resistance of com-

(C) A.P. ZHUDRA, 2014 posite alloys produced using industrial conventional methods of hardfacing, among which the most characteristic method for producing of such alloys is the method of plasma-powder surfacing, which found over the recent years the wide development in the world practice. This method restricts the heat effect of the arc on the granules of carbides during their supply to weld pool that considerably decreases their dissolution in the matrix alloy. The concentration of reinforcing phase in the deposited layer can reach $50 \%$.

For the tests the specimens were prepared deposited using plasma-powder method by composite alloys in one layer. As the reinforcing phase the powders of fused tungsten carbides WC + $\mathrm{W}_{2} \mathrm{C}$ (relite) with traditional crushed and also spherical granules were used. The spherical granules, produced according to the technology of thermal centrifugal spraying of ingots of fused tungsten carbides $[6,7]$ developed at the E.O. Paton Electric Welding Institute, are featured by high microhardness, homogeneous structure and as to the physical and chemical properties they are superior to the similar domestic and foreign materials produced according to other technologies [8, 9].

The granulation of powder of crushed and spherical tungsten carbides was within the limits of $50-250 \mu \mathrm{m}$. The averaged chemical composition and microhardness of both types of carbides are given in Table 1 . 
Table 1. Chemical composition and hardness of tungsten carbides with spherical and crushed particles (tungsten - base)

\begin{tabular}{||c|c|c|c|c|c||}
\hline \multirow{2}{*}{$\begin{array}{c}\text { Type of } \\
\text { granules of } \\
\text { tungsten } \\
\text { carbide }\end{array}$} & \multicolumn{4}{|c|}{ Chemical composition, wt.\% } & \multirow{2}{*}{ Microhardness } \\
\cline { 2 - 6 } & $\mathrm{C}_{\text {total }}$ & $\mathrm{C}_{\mathrm{w}}$ & $\mathrm{Fe}$ & $\begin{array}{c}\text { Impu- } \\
\text { rities }\end{array}$ & HV \\
\hline Spherical & 3.98 & 0.05 & 0.10 & 0.95 & $2600-3100$ \\
\hline Crushed & 3.89 & 0.15 & 0.14 & 1.45 & $1900-2200$ \\
\hline
\end{tabular}

Table 2. Chemical composition and hardness of alloy of matrices (nickel - base)

\begin{tabular}{||c|c|c|c|c|c|c|}
\hline \multirow{2}{*}{$\begin{array}{c}\text { Type of } \\
\text { powder of } \\
\text { matrix alloy }\end{array}$} & \multicolumn{5}{|c|}{ Chemical composition, wt.\% } & Hardness \\
\cline { 2 - 7 } & $\mathrm{C}$ & $\mathrm{Cr}$ & $\mathrm{Si}$ & $\mathrm{B}$ & $\mathrm{Cu}$ & HRC \\
\hline PG-SP2 & 0.53 & 13.82 & 2.43 & 2.25 & - & 58.63 \\
\hline PG-ND42SR & 0.15 & - & 1.05 & 1 & 42.5 & 38.46 \\
\hline
\end{tabular}

For the matrix alloy the powders on nickel base PG-SR2 and nickel-copper base PRND42SR were used, the averaged chemical composition of which is given in Table 2 .

After deposition the thickness of composite layer on the specimens was $5.0-5.5 \mathrm{~mm}$. Here it should be noted that due to a great mass the reinforcing granules of tungsten carbide, as a rule, are located in the lower part of weld pool. Therefore, to obtain the optimal concentration of reinforcing phase on the surface of deposited layer, the specimens were subjected to grinding aflush for the depth of $1.0-1.5 \mathrm{~mm}$. Finally the thickness of deposited layer amounted to about $4 \mathrm{~mm}$, and concentration of carbide inclusions to the tested surfaces of specimens varied in the limits of $45-50 \%$.

As the reference, the specimens were accepted deposited by nickel carbide chromium alloy using flux-cored strip PL AN-111 in three layers with the thickness of deposition of $12 \mathrm{~mm}$ after grinding. The type of deposited metal is 500Kh40N40S2GRTs. The chemical composition of reference specimens is as follows, wt.\%: $5.1 \mathrm{C}$; $34 \mathrm{Cr} ; 36 \mathrm{Ni} ; 2.1 \mathrm{Si} ; 1.2 \mathrm{Mn}$; $0.3 \mathrm{~B}$; $0.3 \mathrm{Zr}$, the hardness of specimens was HRC 52-55.

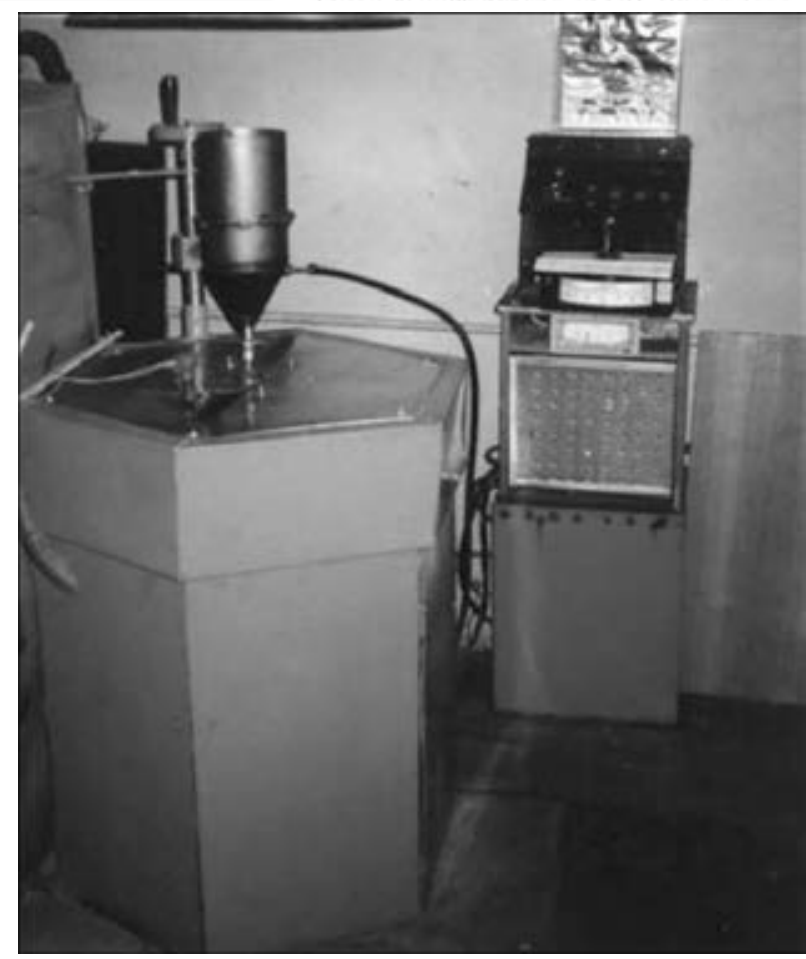

Figure 1. General view of stand OB-876Ts

In all the cases the deposition was performed on the plates of steel of St3 grade $20 \mathrm{~mm}$ thick.

In Table 3 the types of specimens of deposited composite alloys for gas-abrasive wear tests at 25 and $400{ }^{\circ} \mathrm{C}$ are given. Each type of alloy for obtaining the maximum reliable data is represented by three specimens.

The tests on wear resistance of composite alloys, deposited using plasma-powder method, were carried out under the conditions of modeling the gas-abrasive wear on modified stand OB876Ts. The stand allows performing wear of specimens using air-abrasive flow according to the certain scheme.

The acceleration of abrasive parts is performed by centrifugal accelerator in the form of a discrotor, in the centre of which the abrasive in the form of quartz sand of $0.05-0.50 \mathrm{~mm}$ granulation is gravity fed to the receiving hole.

Table 3. Types of specimens for tests on gas abrasive wear

\begin{tabular}{||l|c|c|c|c||}
\hline \multicolumn{1}{|c|}{ Marking of specimens } & Composition of matrix & Hardness of matrix $H R C$ & Type of reinforcing phase & $\begin{array}{c}\text { Hardness of reinforcing } \\
\text { phase } H V 100\end{array}$ \\
\hline KN-1 & $\mathrm{Ni}-\mathrm{Cr}-\mathrm{Si}-\mathrm{B}$ & $58-63$ & $\begin{array}{c}50 \% \text { crushed } \\
50 \% \text { spherical }\end{array}$ & $\begin{array}{c}1800-2200 \\
2800-2930\end{array}$ \\
\hline $\mathrm{KN}-2$ & $\mathrm{Ni}-\mathrm{Cr}-\mathrm{Si}-\mathrm{B}$ & $58-64$ & $100 \%$ spherical & $2650-2880$ \\
\hline $\mathrm{KN}-3$ & $\mathrm{Ni}-\mathrm{Cr}-\mathrm{Si}-\mathrm{B}$ & $54-59$ & Same & $2730-3000$ \\
\hline $\mathrm{KM}-4$ & $\mathrm{Ni}-\mathrm{Cu}-\mathrm{Si}-\mathrm{B}$ & $38-46$ & » & $2750-3050$ \\
\hline KM-5 & $\mathrm{Ni}-\mathrm{Cu}-\mathrm{Si}-\mathrm{B}$ & $39-49$ & - & $2800-2980$ \\
\hline Reference specimen & $\mathrm{C}-\mathrm{Cr}-\mathrm{Ni}-\mathrm{Si}-\mathrm{Mn}$ & $55-62$ & & - \\
\hline
\end{tabular}




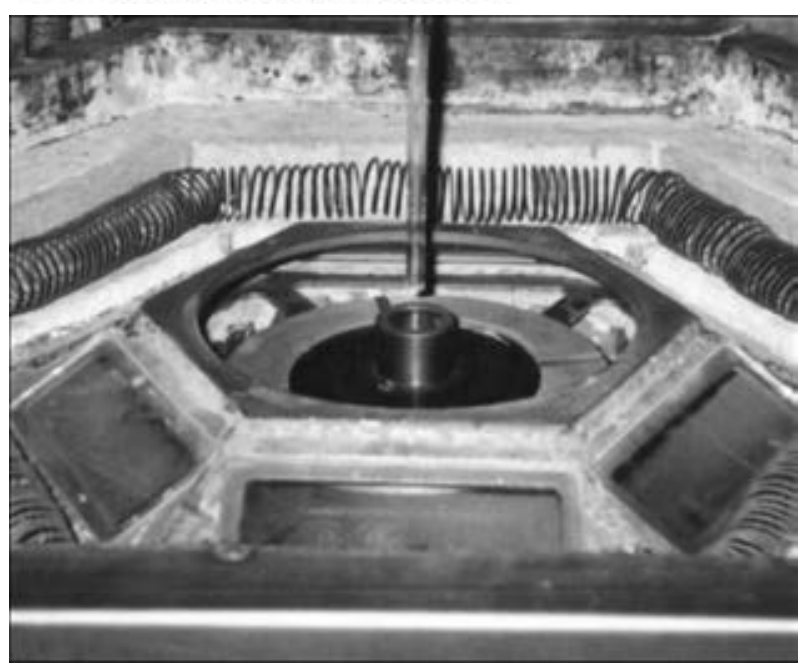

Figure 2. Cassette with specimens in heating chamber

The particles of sand are accelerated along four inner channels up to $200 \mathrm{~m} / \mathrm{s}$. Having achieved the outer diameter of rotor, the abrasive flow overcomes the air gap of $25 \mathrm{~mm}$ length and by the impacts of abrasive particles is wearing out the working surfaces of simultaneously six specimens of $170 \times 70 \times 19 \mathrm{~mm}$. Here the angle of attack of abrasive with respect to the surface of specimens amounts to $15^{\circ}$. The cassette with specimens is located in the chamber, the temperature in which can be controlled in the limits of $25-450{ }^{\circ} \mathrm{C}$. The general view of stand OB876Ts and cassette with specimens are shown in Figures 1 and 2, and its main technical characteristics are represented below.

\section{Technical characteristics of stand OB-876Ts}

Rotor diameter, $\mathrm{mm}$.................................. 220

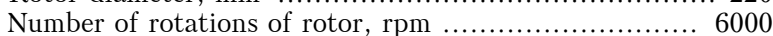

Angle of attack of abrasive flow, deg .................. 5-70

Temperature of heating of specimens, ${ }^{\circ} \mathrm{C} \ldots \ldots \ldots \ldots$ up to 400

Duration of heating of specimens up to $400{ }^{\circ} \mathrm{C}, \mathrm{h}$........ 3.5

Consumption of abrasive, $\mathrm{cm}^{3} / \mathrm{s} \ldots \ldots \ldots \ldots \ldots \ldots \ldots . \ldots . \ldots . . .6 .3$

Capacity of electric motor of rotor drive, $\mathrm{kW} \ldots \ldots \ldots \ldots . . \ldots .75$

Number of test specimens, pcs ........................... 6

The wear of specimens was evaluated according to the decrease in volume in $\mathrm{cm}^{3}$, which was determined by the method of hydrostatic weighing. Also the intensity of wear in $\mathrm{cm}^{3}$ during consumption of each $100 \mathrm{~kg}$ of abrasive and relative wear resistance as to the reference, deposited by nickel carbide chromium alloy, were determined. The averaged data of investigations of three specimens of each type of composite alloy are given in Figure 3.

As it was expected, the general regularity of wear of composite alloys in gas-abrasive wear is its selectivity and cycling, i.e. change of wear resistance with time. Initially the matrix is worn out intensively, stripping the carbides, which protect matrix and sufficiently delay the wear of

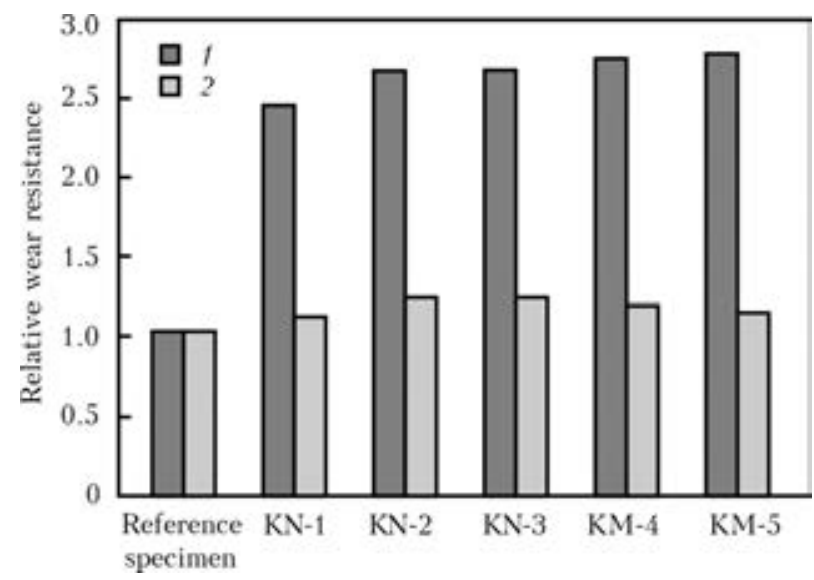

Figure 3. Relative wear resistance of specimens of composite alloys at 25 (1) and $400(2){ }^{\circ} \mathrm{C}$

alloy due to the shadow effect. After wear of matrix and washing out of carbides the cycle is repeated. The obtained results correlate well with the data of investigations described in [2].

At the angle of attack of abrasive of $15^{\circ}$ the composition of matrix and its hardness practically does not influence the wear resistance of the composite alloy.

Under the conditions of room temperature the highest wear resistance belongs to composite alloys $\mathrm{KN}-2, \mathrm{KN}-3$ composed of spherical granules of tungsten carbide and matrices of the $\mathrm{Ni}-\mathrm{Cr}-$ $\mathrm{Si}-\mathrm{B}$ type. Their wear resistance approximately 2.7 times exceeds the wear resistance of reference specimen of nickel carbide chromium alloy. Alloy $\mathrm{KN}-1$ with the similar matrix, but containing the mixture of spherical and crushed granules of tungsten carbides, possesses wear resistance of approximately lower by $10-12 \%$, that corresponds to the lower strength characteristics of crushed particles as compared to the spherical ones.

At $400{ }^{\circ} \mathrm{C}$ the wear resistance of composite alloys decreased considerably, though the tendency of increased resistance of compositions with spherical granules of carbides, as compared to the mixture, preserved. The increase in wear at elevated temperatures is, first of all, connected with oxidizing processes of the carbide component of alloys. The wear of tungsten carbides occurs not only due to the effect of abrasive flow, but also due to their oxidation. This factor should be considered during hardening of parts using composite alloys based on tungsten carbides operating at high temperatures in the oxidizing environment. In the restoration or inert environments the temperature almost does not influence the wear resistance of composite alloys. At the practice this is observed during operation of charging equipment of blast furnaces after hardfacing by composite alloys based on relite, which are operated in the restoration gas environment. 
This equipment is labor-intensive in manufacture, however its resistance several times exceeds the equipment after hardfacing by carbide-chromium alloys.

\section{Conclusions}

1. The wear of composite alloys on the basis of fused tungsten carbides under the conditions of effect of gas abrasive flow bears selective, cyclic nature and negligibly depends on properties and hardness of matrix at the angle of attack of $15^{\circ}$.

2. Even partial use of spherical granules of tungsten carbide as the reinforcing phase instead of crushed increases the wear resistance of composite alloy by $10-12 \%$.

3. Wear resistance of composite alloys under the conditions of gas-abrasive wear at the room temperature approximately 2.7 times exceeds the wear resistance of nickel carbide chromium alloy, and at the temperature of $400{ }^{\circ} \mathrm{C}$ it decreases considerably due to oxidation of carbide component of the alloy.
1. Tereshchenko, N.F., Gavrish, V.A. (1971) Resistance of alloys in gas-and-abrasive wear. Fiz.-Khimich. Mekhanika Materialov, 4, 18-21.

2. Yuzvenko, Yu.A., Zhudra, A.P., Frumin, E.I. et al. (1972) Peculiarities of gas-and-abrasive wear of composite alloys. Avtomatich. Svarka, 8, 35-38.

3. Yuzvenko, Yu.A., Zhudra, A.P., Frumin, E.I. (1973) Abrasive wear of composite alloys. Ibid., 7, 62-63.

4. Yuzvenko, Yu.A. (1978) Investigation and development of materials and technologies of mechanized open-arc surfacing: Syn. of Thesis for Dr. of Techn. Sci. Degree. Kiev: PWI.

5. Yuzvenko, Yu.A., Gavrish, V.A. (1972) Machine for assessment of wear resistance of deposited metal in gasand-abrasive erosion. Avtomatich. Svarka, 6, 73-74.

6. Litvinenko, A.I., Zhudra, A.P., Bely, A.I. (2013) Analysis and kinetics of centrifugal spraying of ingots from fused tungsten carbides. Sovr. Elektrometallurgiay, 2, 29-36

7. Dzykovich, V.I. (2009) Effect of the centrifugal thermal spraying process on properties of spherical tungsten carbide particles. The Paton Welding J., 4, 43-45.

8. Dzykovich, V.I., Zhudra, A.P., Bely, A.I. (2010) Properties of tungsten carbide powders produced by different technologies. Ibid., 4, 22-24.

9. Bely, A.I. (2010) Wear resistance and strength of tungsten carbides $\mathrm{WC}-\mathrm{W}_{2} \mathrm{C}$ produced by different methods. Ibid., 12, 15-17.

Received 01.10.2014 